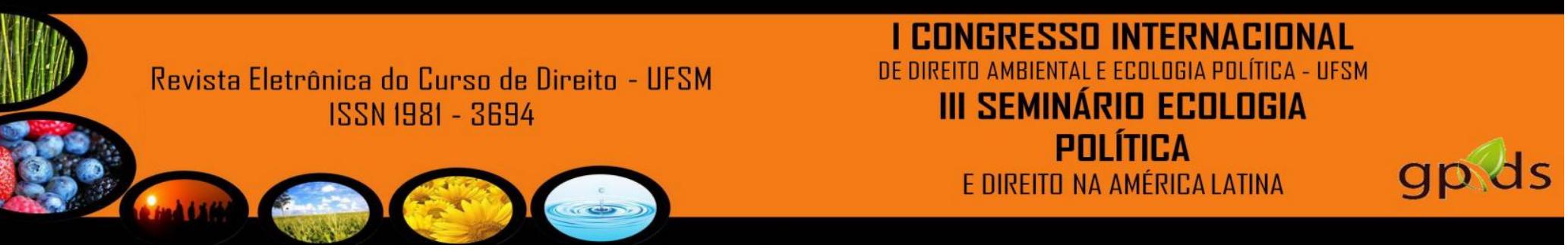

\title{
A CRISE ENTRE O MODO DE PRODUÇÃO CAPITALISTA E A FINITUDE DOS RECURSOS NATURAIS: A ASCENSÃO DE UM NOVO MODELO ÉTICO COMO ALICERCE DE UM ESTADO AMBIENTAL DE DIREITO
}

Fabiano Rodrigues Lima ${ }^{1}$ Viviane Teixeira Dotto Coitinho ${ }^{2}$

\section{RESUMO}

A alta velocidade com que se desenvolve a sociedade no campo da tecnologia é contrária à garantia do mínimo existencial, desencadeando, assim, o processo de desequilíbrio ambiental, pois a contínua exploração desenfreada acarretará a falta de condições para a existência humana. Sendo necessário notar a enorme importância que a preservação da biodiversidade representa aos cidadãos. No que concerne à diversidade das espécies, a sua funcionalidade destaca-se no fornecimento de recursos para os seres humanos, além de representar o alcance das adaptações evolucionárias e ecológicas das espécies em determinados ambientes. Desta forma, o presente trabalho busca analisar a crise entre o modo de produção capitalista e a finitude dos recursos naturais trazendo a ascensão de um novo modelo ético como alicerce de um estado ambiental de direito.

PALAVRAS-CHAVE: Desenvolvimento Econômico, Sustentabilidade; Estado Ambiental de Direito.

\section{INTRODUÇÃO}

Diante de um paradigma ostentado pelo Estado Liberal individualista, o qual é obstinado ao desenvolvimento da economia capitalista, o meio ambiente torna-se um mero instrumento para a atividade desenfreada das indústrias e ao acúmulo de riquezas e capitais, sendo manipulado de maneira dominadora e não tão pouco predatória sob a tutela de um modelo patrimonial e utilitário.

Esta atitude assumida pelo ser humano traz a tona a sua própria racionalidade na forma de agir e pensar, pois nem mesmo a respostas dispensadas pela natureza, sinalizadas em catástrofes naturais, merecem uma maior compreensão acerca dos atos praticados por ele.

Notamos que este modelo preconizado fundamentava-se no conceito de que os recursos naturais eram inesgotáveis e o mundo um maquina insaciável de produção, com a tarefa de suprir as demandas crescentes de um mundo consumista. A ciência e os avanços tecnológicos seriam ferramentas utilizadas para incrementar formas de

\footnotetext{
${ }^{1}$ Autor/apresentador. Acadêmico do $3^{\circ}$ semestre do curso de Direito da Faculdade Palotina de Santa Maria-RS.

Correio eletrônico: fabano01@hotmail.com

2 Coautora/orientadora. Mestre em Direito pela UNISC - Universidade de Santa Cruz do Sul e Especialista em Direito Processual Civil pela PUCRS - Pontifícia Universidade Católica do Rio Grande do Sul (RS). Professora nas disciplinas de Direito Civil e Bioética pela Fadisma - Faculdade de Direito de Santa Maria (RS), Direito Tributário, Direito Civil e Bioética pela Fapas - Faculdade Palotina. Correio eletrônico: vividotto@bol.com.br.
} 
exploração e dominação da natureza, com o objetivo de extrair dela o máximo de matéria-prima para o avanço industrial.

Instaura-se uma crise a partir do momento em que o modo de produção, predador e voraz, capitalista e o desenvolvimento econômico choca-se com a finitude dos recursos da natureza, dando margem a concepção de que a relação ser humano/natureza deve ser regido pela ética, fundamentada na compatibilidade da preservação do meio ambiente com o desenvolvimento econômico sustentável e responsável.

Diante do exposto, procuraremos discutir a postura do ser humano diante do meio ambiente em que vive, refletindo na criação de um novo modelo ético visando à constituição de um Estado Ambiental de Direito. Para tanto abordaremos as concepções antropocêntricas e biocêntricas acerca da relação natureza/ser humano, discorrendo sobre a ascensão de um novo modelo ecológico, para, finalmente, tratar sobre a constituição de um Estado Ambiental de Direito.

\section{ANTROPOCENTRISMO X BIOCENTRISMO}

A atividade humana, durante o seu processo de civilização baseava-se na obtenção de recursos naturais exclusivamente para a sua sobrevivência e preservação da espécie, não havendo espaço para valoração destes bens para outros fins. Ao longo dos anos, com o aparecimento e descobrimento de novas tecnologias, passou a ser vislumbrada uma exploração sem precedente, calcada em sistema de produção de cunho predador e dominador, tendo como produto uma crise ecológica, a qual teve reflexo na relação incompatível entre o homem e a natureza, consequente do modelo de intervenção no meio ambiente, alicerçada em uma visão equivocada de que os recursos naturais jamais acabariam.

Estabelecida esta crise ecológica, muito ligada ao modelo escolhido de intervenção e relacionamento do ser humano com a natureza, abra-se um campo para discutir a ética no âmbito da ecologia. Neste contexto, cabe ressalta (JUNGES, 2004), que o debate ecológico expõe questões fundamentais para a ética. Discute o próprio ponto de partida e a abrangência dos sujeitos de consideração da ética. Assim, foram surgindo enfoques antropocêntricos ou biocêntricos na discussão da ética da ecologia. 
Os primeiros dizem que o ser humano detém um protagonismo no mundo. Busca a solução para os problemas ambientais na perspectiva do papel central do ser humano em relação à natureza. Os biocêntricos defendem que o ser humano é apenas um elemento a mais no ecossistema da natureza, um elo entre muitos na cadeia de reprodução da vida. Por isso, o protagonismo pertence à vida e a crise ecológica precisa ser equacionada numa perspectiva biocêntrica.

A concepção antropocêntrica teve considerável aceitação no mundo ocidental por causa do modelo racionalista, difundido por Descartes, segundo o qual o homem é dotado de razão, o que lhe atribui a faculdade de dar finalidade a tudo o que existe.

Segundo esta concepção (FIORILLO, 2010), um bem que não seja vivo (material ou imaterial), assim como uma vida que não seja humana, poderá ser tutelado pelo direito ambiental na medida em que sua existência implique garantia da sadia qualidade de vida do ser humano, uma vez que numa sociedade organizada este é o destinatário de toda e qualquer norma. $\mathrm{Na}$ verdade, o direito ambiental possui uma necessária concepção antropocêntrica, porquanto o único animal racional é o homem, cabendo a este a preservação das espécies, incluindo a sua própria.

No entanto, ressaltando a ação predatória utilizada pelo homem, há de se admitir de que a ideia de que o homem domina e submete o meio ambiente à exploração ilimitada está ultrapassada, pois hoje a defesa do meio ambiente está relacionada a um interesse intergeracional e com necessidade de um desenvolvimento sustentável, com o objetivo de preservar os recursos naturais para as gerações vindouras, fazendo com que a proteção antropocêntrica outrora perca força, pois está em jogo não apenas o interesse da geração atual. Assim, este novo modelo de proteção ambiental, com vistas às gerações futuras, pressiona um comportamento humano, politico e coletivo mais consciencioso com relação às necessidades ambientais (LEITE, AYALA; 2002).

Trata-se de um alargamento desse conceito que acentua a responsabilidade do ser humano pela natureza e justifica a atuação deste guardião da biosfera.

Ao contrario ao conceito antropocêntrico, o biocentrismo não aceita o tratamento diferenciado entre os seres humanos e natureza, considerando que a proteção 
III SEMINÁRII ECDLOGIA

POLÍTICA

A referida crise de percepção, expressão preconizada por Capra, deriva do fato de que as maiorias das pessoas, em especial as grandes instituições sociais, concordam com os conceitos de uma concepção de mundo ultrapassada, uma percepção da realidade imprópria para lidar com o mundo superpovoado e globalmente conexo. Sendo assim, a crise ambiental global exige uma mudança radical de modelo, indo de um reducionismo cartesiano para uma cultura de uma análise sistêmica do meio ambiente. Resumindo, o grande desafio consiste na promoção da mudança do atual modelo que influencia a economia global para um modelo compatível com sustentabilidade ecológica.

O método cartesiano, usado pelo sistema produtivo global, consiste em quebrar os fenômenos complexos em partes a fim de compreender o comportamento do todo a partir da análise e do conhecimento das propriedades das suas partes. Em contrapartida, o modelo mecanicista de Descartes impõe uma análise fragmentada da realidade, tornando-se um fator determinante na visão de que o ser humano ocupa papel central de dominação e subordinação dos demais seres.

Com isso, o pensamento sistêmico surge como alternativa para romper com a concepção centralizadora do ser humano em detrimento aos outros seres do meio em que habita. Um sistema não mais voltado a um modelo predatório e dominador, mas sim para um modelo inovador, sistêmico e principalmente solidário. É a preconização de um modelo holístico, como um todo interligado e interdependente, constituindo uma teia relacional entre os seres vivos e a biosfera.

Mas, embora a crise ambiental estabelecida pela ação humana exponha a necessidade de uma nova relação entre o ser humano e o meio ambiente centrada numa postura ética diante da natureza, é perceptível que o homem contemporâneo não se desvinculou do modo de produção e de consumo introduzidos e incentivados pela modernidade, ganhando campo, pois, nesse entendimento, a necessidade de um novo conceito de Estado Ambiental de Direito (CUSTÓDIO, BALDO; 2012).

\section{MEIO AMBIENTE ECOLOGICAMENTE EQUILIBRADO: UM DIREITO FUNDAMENTAL}




